\title{
Botryotrichum and Scopulariopsis Secondary Metabolites and Biological Activities
}

\author{
Waill A. Elkhateeb ${ }^{1 *}$, Ghoson M. Daba ${ }^{1}$ \\ ${ }^{1}$ Chemistry of Natural and Microbial Products Department, National Research Centre, Dokki, Giza, 12622, Egypt.
}

*Corresponding Author: Waill A. Elkhateeb, Chemistry of Natural and Microbial Products Department, National Research Centre, Dokki, Giza, 12622, Egypt.

Received date: November 17, 2021; Accepted date: December 15, 2021; Published date: January 05, 2022

Citation: Waill A. Elkhateeb, Ghoson M. Daba (2022) Botryotrichum and Scopulariopsis Secondary Metabolites and Biological Activities. J, Biotechnology and Bioprocessing 3(1); DOI: 10.31579/2766-2314/067

Copyright: (C) 2022, Waill A. Elkhateeb, This is an open access article distributed under the Creative Commons Attribution License, which permits unrestricted use, distribution, and reproduction in any medium, provided the original work is properly cited.

\begin{abstract}
Botryotrichum and Scopulariopsis are a fungal genera that belongs to Class: Sordariomycetes. This review is to demonstrate secondary metabolites from Botryotrichum and Scopulariopsis and some of their reported biological activities. Moreover, describing the unique chemical diversity of these fungal genera involved in medical, pharmaceutical, agricultural applications. Also highlight the harmful side of these fungi if present.
\end{abstract}

Keyword: botryotrichum; scopulariopsis; secondary metabolites; biological activities

\section{Introduction}

Natural products have, historically, played an important role in drug discovery. Fungal natural products with diverse chemical structures and biological activities are rich resources of both drugs and toxins, thus causing Janus-like effects on human beings [1-3]. Significant progress has been made in discovery and mining of novel fungal Natural products in the past decades. The kingdom Fungi represents an incredibly rich and untapped source of bioactive natural products and seems to be an ideal agent for providing unique chemical compounds against various diseases [4-6]. They are present in almost every ecological niche, making them the second largest kingdom after insect and bacteria. Many reports represent that earth is approximately estimated to have 1.5 million species and only $10 \%$ of it is known to scientific community. The variety of genera and species and the variety of their habitats, made fungi great source of different natural product [7-9].

Today, mankind is not only still facing the challenge to treat untamed diseases, but is also fighting newly recognized diseases, and diseases that once were subdued but are developing resistance to the current therapeutic regimes [10-12]. Several fungal secondary metabolites are useful for human life, for example, penicillin a $\beta$-lactam antibiotic was isolated first time from Penicillium sp. Now, it is one of the widely used antibiotics worldwide. Fungal kingdom produces a variety of secondary metabolites, including all important classes like terpenes, terpenoids, alkaloids, and sugar derivatives. Today many scientists around the world is searching for a chemical method to synthesize the secondary metabolite in laboratory at higher yield for getting the most benefits [1317].

Fungal natural products have provided revolutionary pharmaceuticals against various diseases, and have provided unique and inspirational chemicals for innovative drugs. Fungi are essential source of drugs in spite of many remarkable therapeutic agents discovered from them so far. But only a small fraction of the fungal taxa can be and have been fermented in laboratory media for drug discovery [18-20]. Fungal secondary metabolites exhibit biological activities that have been developed into life-saving medicines and agrochemicals and also produced toxic metabolites, known as mycotoxins, contaminate human and livestock food and indoor environments. The present review focuses on the two different genus Botryotrichum and Scopulariopsis natural products and highlighting the originality of the structures and their biological potential and their harmful if present.

\section{Botryotrichum and Scopulariopsis, description and ecology}

The genus Botryotrichum belonging to phylum: Ascomycota; Class: Sordariomycetes; Order: Microascales; Family Microascaceae. Conidiophores indistinguishable; Conidia (aleurioconidia) produced singly on short stalks, or sometimes in botryose clusters, large, globose, thick-walled; sterile hairs present, erect or sub-erect, tapering acutely at the apex, mostly roughened, dracker below, hyaline or subhyaline above; Phialoconidia sometimes present, phialides short, arising directly from vegetative hyphae, conidia hyaline, produced in chains, but sometimes slime down into a ball-like mass. Colonies attaining $3.5 \mathrm{~cm}$ in diameter after 10 days on malt extract agar at $25 \mathrm{C}$, whitish at first but gradually changing into light brown or buff colour [12]. The most common species is Botryotrichum piluliferum. Botryotrichum is commonly found in soils especially those high in organic matter (Figure, 1).

The genus Scopulariopsis belonging to phylum: Ascomycota; Class: Sordariomycetes; Order: Sordariales; Family: Chaetomiaceae. Colonies white, buff or black, never true green, velvety or funiculose; hyphae hyaline or pigmented; Conidiophores macronematous or semi- 
macronematous, usually short to very short, branched with branches mostly confined to the apical region; Conidiogenous cells monoblastic, closely annellate, also called annellophores, ampulliform, elliptical or cylindrical, produced singly or in whole in a pencillate arrangement; Conidia one-celled produced in chains of basipetal succession, dry, elliptical, pyriform, globose or subglobose, truncate with a rim at the base, colourless to brown, smooth to verrucose. Colonies attaining $6 \mathrm{~cm}$ in diameter after 10 days on Czapeks+yeast extract agar at 25C, at first whitish, later Orange-White, with a narrow white margin, surphace powdery [12]. The most common species s Scopulariopsis brevicaulis and is commonly found in soils (Figure, 2).

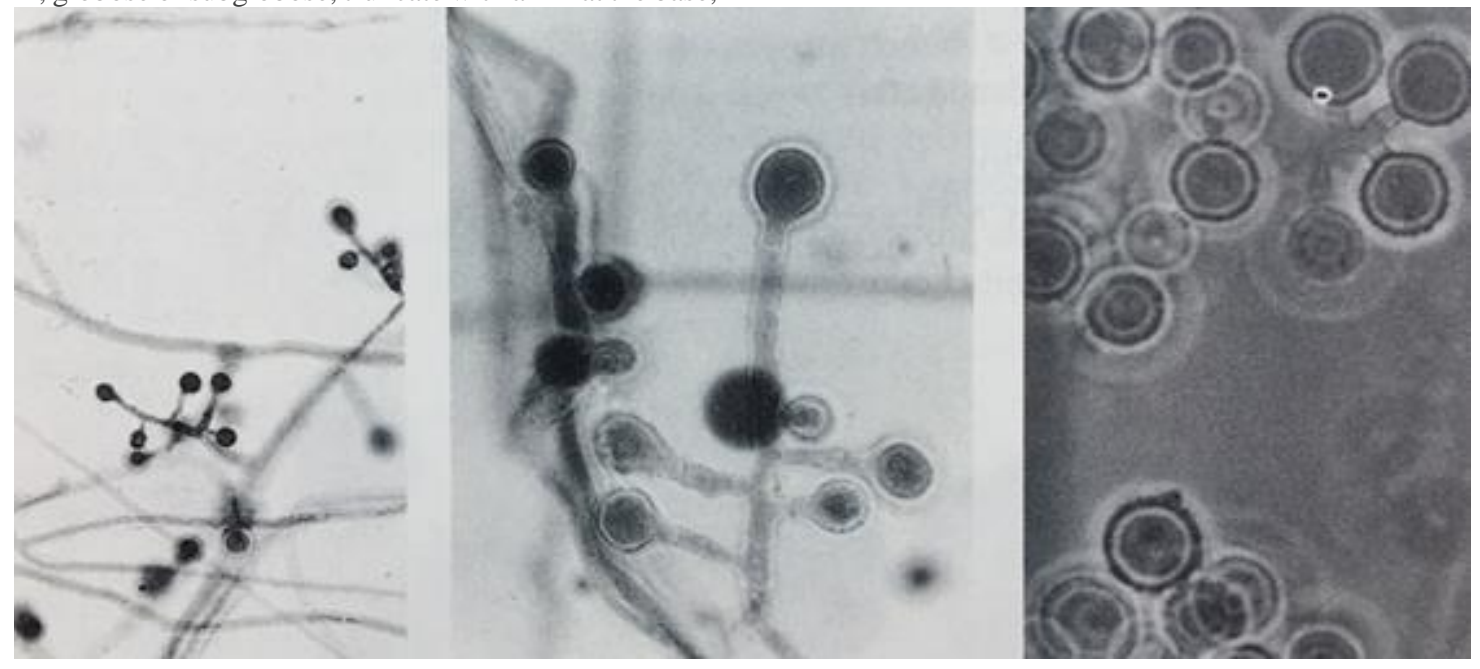

Figure (1). Botryotrichum spp., different species, Photo was taken by Dr. Moubasher AH. Assiut University.

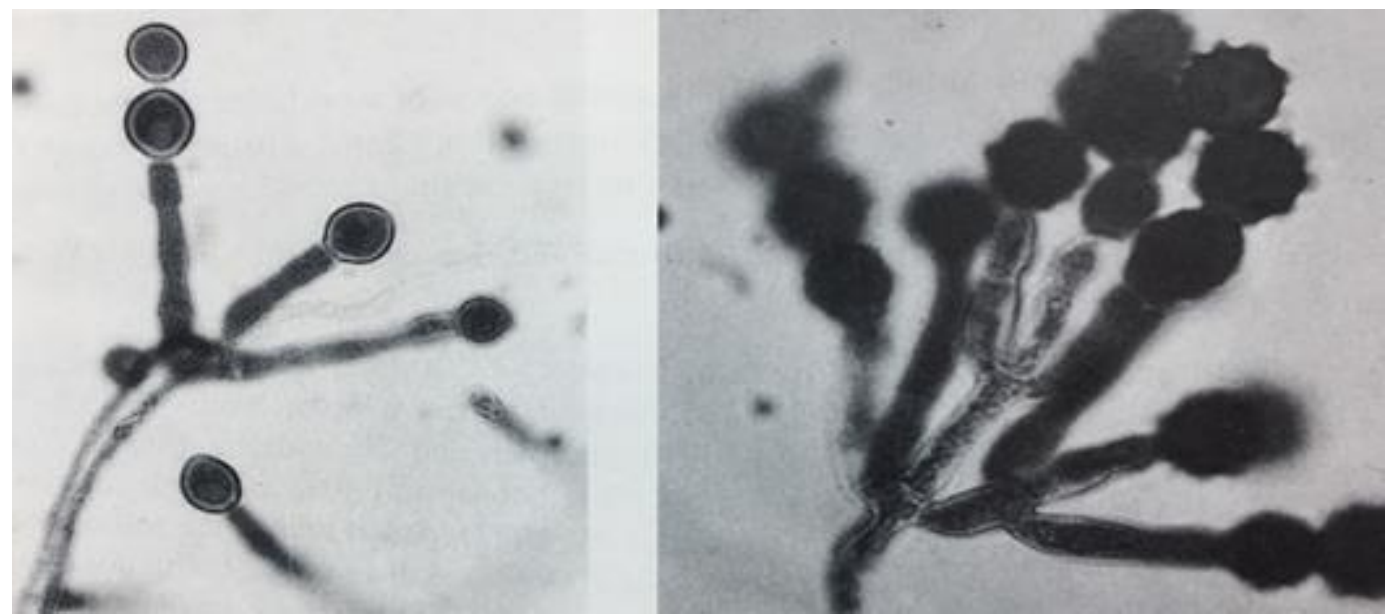

Figure (2). Scopulariopsis spp., different species, Photo was taken by Dr. Moubasher AH. Assiut University.

\section{Botryotrichum and Scopulariopsis as source of biologically} active compounds

Fungal secondary metabolites exhibit biological activities that have been developed into life-saving medicines and agrochemicals. However some of these metabolites exhibited unfavourable activities. The genus Botryotrichum produced many secondary metabolites. Four new decarestrictine analogues (botryolides A-D), a biosynthetically related $\gamma$ lactone (botryolide $\mathrm{E}$ ), and the known compounds decarestrictine $\mathrm{D}$ and sterigmatocystin have been isolated by Sy et al., [21], from cultures of a fungicolous isolate of Botryotrichum sp. (NRRL 38180). The structures of these compounds were determined by analysis of 2D NMR and ESIMS data. The relative configurations of botryolides $\mathrm{A}-\mathrm{D}$ and botryolide E were established on the basis of NMR data and/or X-ray diffraction analysis [21]. Chromatographic analysis of a crude ethyl acetate extract derived from a solid rice culture incubated at $40^{\circ} \mathrm{C}$ inoculated by the extremophilic fungus Botryotrichum piluliferum strain WESH19 yielded a new natural butenolide compound (1) together with three known metabolites (2-4). Chemical structures of isolated metabolites were confirmed via HRESIMS along with 1D- and 2D-NMR spectroscopic analyses. Compounds (1-3) revealed significant antimicrobial activities against Staphylococcus aureus (ATCC 700699), Enterococcus faecalis (ATCC 29212), Enterococcus faecium (ATCC 35667) while their antifungal activities were evaluated against the extremophilic fungus Penicillium simplicissimum strain WSH17 [22].

Rajachan et al., [23], reported that, two new sterigmatocystin derivatives, oxisterigmatocystins $\mathrm{E}$ and $\mathrm{F}$, along with nine known compounds, oxisterigmatocystins $\mathrm{G}$ and $\mathrm{H}$, sterigmatocystin, N-0532B, Omethylsterigmatocystin, N-0532A, 6-O-methylversicolorin A, 6,8-Odimethylversicolorin $\mathrm{A}$, and 8-O-methylaverufin, were isolated from Botryotrichum piluliferum. Among these, compounds oxisterigmatocystins $\mathrm{G}$ and $\mathrm{H}$, and 6-O-methylversicolorin A, were discovered as natural products for the first time. Oxisterigmatocystins E, oxisterigmatocystins G, and oxisterigmatocystins $\mathrm{H}$ displayed antimalarial activity toward Plasmodium falciparum. In addition, all these compounds except $\mathrm{O}$ methylsterigmatocystin, exhibited cytotoxicity against $\mathrm{KB}, \mathrm{MCF}-7$, and 
NCI-H187 cell lines. From all these results finding should promote awareness of the contamination of Botryotrichum piluliferum in the food chain and agricultural soil [23].

Marine fungi and, mainly, endophytic species have been recognised as one of the most prolific sources of structurally new and diverse bioactive secondary metabolites with multiple biotechnological applications [24]. Marine organisms especially fungi produce many novel compounds with useful biological activity, but are currently underexploited, Youssef and Simal-Gandara, [25], reported that Scopulariopsis fungi isolated from marine source produced alkaloid metabolites showed considerable effect with respect to the tested activities. Most of the reported bioactive alkaloids showed considerable biological activities mainly cytotoxic followed by antibacterial, antifungal, antiviral, antioxidant, and required further investigations for additional biological activities. Thus, alkaloids isolated from marine-associated fungi can afford an endless source of new drug entities that could serve as leads for drug discovery combating many human ailments [25].

Many researches have been invested compounds from marine fungi, and concluded that marine fungi produce an interesting range of compounds $[26,27]$. During product discovery, these compounds are often produced only in non-agitated culture conditions, which are unfortunately not well suited for scaling up. A marine isolate of Scopulariopsis brevicaulis, strain LF580, produces the cyclodepsipeptide scopularide A, which has previously only been produced in non-agitated cultivation. Scopulariopsis brevicaulis LF580 produced scopularide A when grown in batch and fed-batch submerged cultures [28].

Yu et al., [29], reported that, two novel cyclodepsipeptides, scopularides A and B, were found in the fungus Scopulariopsis brevicaulis extracted by ethyl acetate, which was isolated from the marine sponge Tethya aurantium. In addition, the known fungal metabolite paxilline was identified. The structures of the scopularides were elucidated by NMR, MS, and chemical derivatization methods as cyclo-(3-hydroxy-4methyldecanoyl-Gly-1-Val-d-Leu-1-Ala-1-Phe), and cyclo-(3-hydroxy4-methyloctanoyl-Gly-1-Val-d-Leu-1-Ala-1-Phe) for scopularide A and $\mathrm{B}$, respectively. Antibiotic activity against Gram-negative bacteria was absent and against Gram-positive bacteria was weak, but activity against several tumor cell lines was significant at $10 \mu \mathrm{g} / \mathrm{mL}$ [29].

Scopularide A is a promising potent anticancer lipopeptide isolated from a marine derived Scopulariopsis brevicaulis strain [30]. The compound consists of a reduced carbon chain (3-hydroxy-methyldecanoyl) attached to five amino acids (glycine, 1-valine, d-leucine, 1-alanine, and 1phenylalanine). Using the newly sequenced Scopulariopsis brevicaulis genome we were able to identify the supposed biosynthetic gene cluster. The scopularide A gene cluster includes a nonribosomal peptide synthetase (NRPS1), a polyketide synthase ( $P K S 2)$, a CoA ligase, an acyltransferase, and a transcription factor. Homologous recombination was low in Scopulariopsis brevicaulis so the local transcription factor was integrated randomly under a constitutive promoter, which led to a three to four-fold increase in scopularide A production [30].

Ticks and Tick-Borne Diseases are widespread in the Sudan causing substantial losses in terms of morbidity, mortality, reduction of production and costs of control and treatment. Control of ticks is based mainly on chemical acaricides. Scopulariopsis brevicaulis was isolated and its identification was based on macro and microscopic characteristics. Metabolite profiling of Scopulariopsis brevicaulis culture filtrate was detected on thin layer chromatography and organic compounds were detected. Pathogenicity of the spore suspension and culture filtrate of the isolated Scopulariopsis brevicaulis to larvae, nymph and adult stages of Hyalomma anatolicum and Amblyomma lepidum was investigated by Suleiman et al., [31]. High mortality to flat larvae and biotic potential of the adult were observed. Results obtained stimulate the use of Scopulariopsis brevicaulis metabolites as biological control agents for controlling ticks in Sudan [31].

\section{Conclusion}

Fungi are important source of unique natural products with a high level of biodiversity and produce several compounds having different pharmaceutical activities and other different applications, which is currently attracting scientific researchers. Every study conducted on Botryotrichum and Scopulariopsis resulted in discovery of new metabolites or pointing to a possible application, which made these genera promising source of pharmaceuticals and attracted attention for further investigations of their important bioactivities properties.

\section{References}

1. Elkhateeb WA, Daba GM. (2018). Where to Find? A Report for Some Terrestrial Fungal Isolates, and Selected Applications Using Fungal Secondary Metabolites. Biomed Journal Science \&Technology Research, 4(4): 1-4.

2. Elkhateeb WA, Daba GM. (2019). The amazing potential of fungi in human life. ARC J. Pharma. Sci. AJPS, 5(3): 12-16.

3. Elkhateeb WA, Daba GM. (2019). Epicoccum species as potent factories for the production of compounds of industrial, medical, and biological control applications. Biomedical Journal of Scientific and Technical Research, 14: 10616-10620.

4. Elkhateeb WA, Daba GM. (2019). Myrothecium as promising model for biotechnological applications, potentials and challenges. J. Sci. Res, 16: 12126-12131.

5. Daba GM, Mostafa FA, Elkhateeb WA. (2021). The ancient koji mold (Aspergillus oryzae) as a modern biotechnological tool. Bioresources and Bioprocessing, 8(1): 1-17.

6. Daba GM, Elkhateeb WA, Thomas PW. (2018). This era of biotechnological tools: an insight into endophytic mycobiota. Egyptian Pharmaceu J, 17(3): 121-128.

7. Elkhateeb WA, EL-Ghwas DE, AL Kolaibe AG, Akram M, Daba GM (2021). Yeast the Present and Future Cell Facture. Journal of Mycology \& Mycological Sciences, 4(2): 1-5.

8. Elkhateeb WA, Elnahas MO, Daba GM, Zohri AN. (2021). Biotechnology and Environmental applications of Trichoderma spp. Research Journal of Pharmacognosy and Phytochemistry, 13(3): 149-157.

9. Elkhateeb WA, Kolaibe AG, Daba GM. (2021). Cochliobolus, Drechslera, Bipolaris, Curvularia different nomenclature for one potent fungus. Journal of Pharmaceutics and Pharmacology Research, 4(1): 1-6.

10. Elkhateeb WA, Kolaibe AG, Elnahas MO, Daba GM. (2021). Highlights on Chaetomium morphology, secondary metabolites and biological activates. Journal of Pharmaceutics and Pharmacology Research, 4(1): 1-5.

11. Hawas UW, Ahmed E, Halwany A, Atif A, Elkhateeb WA, Abou El-Kassem LT. (2016). Bioactive metabolites from the Egyptian Red Sea Fungi with potential anti-HCV protease effect. Chemistry of Natural Compounds, 52(1): 104-110.

12. Elkhateeb WA. (2005). Some mycological, phytopathological and physiological studies on mycobiota of selected newly reclaimed soils in Assiut Governorate, Egypt (M. Sc. Thesis, Faculty of Science, Assuit University, Egypt. 2005; p 238.

13. Elkhateeb WA, Zohri AA, Mazen M, Hashem M, Daba GM. (2016). Investigation of diversity of endophytic, phylloplane and phyllosphere mycobiota isolated from different cultivated plants in new reclaimed soil, Upper Egypt with potential biological applications, Inter J MediPharm Res, 2(1): 23-31.

14. Elnahas MO, Elkhateeb WA, Daba GM. (2020). All in one Thermoascus aurantiacus and its Industrial Applications. 
International Journal of Pharma Research and Health Sciences, 8 (5): 3231-3236.

15. Elkhateeb WA, Daba GM. (2021). Stemphylium and Ulocladium between Benefit and Harmful. J Biomed Res Environ Sci. 20; 2(11): 1117-1120.

16. Singh AK, Rana HK, Pandey AK. (2019). Fungal-Derived Natural Product: Synthesis, Function, and Applications. In Recent Advancement in White Biotechnology Through Fungi (pp. 229248). Springer, Cham.

17. Schueffler A, Anke T. (2014). Fungal natural products in research and development. Natural product reports, 31(10): 1425-1448.

18. Jiang ZD, Zhiqiang AN. (2000). Bioactive fungal natural products through classic and biocombinatorial approaches. Studies in Natural Products Chemistry, 22: 245-272.

19. Hoffmeister D. (2018). Fungal natural products-organismal diversity, seen from the (bio) chemical angle. Biosyst. Ecol. Ser., 34: 419-428.

20. Keller NP. (2019). Fungal secondary metabolism: regulation, function and drug discovery. Nature Reviews Microbiology, 17(3): 167-180.

21. Sy AA, Swenson DC, Gloer JB, Wicklow DT. (2008). Botryolides A- E, Decarestrictine Analogues from a Fungicolous Botryotrichum sp. (NRRL 38180). Journal of natural products, 71(3): 415-419.

22. Ebrahim W, Ebada SS. (2021). Antimicrobial Metabolites from Extremophilic Fungus Botryotrichum piluliferum Strain WESH19. Chemistry of Natural Compounds, 57(4): 654-658.

23. Rajachan OA, Kanokmedhakul K, Soytong K, Kanokmedhakul S. (2017). Mycotoxins from the fungus Botryotrichum piluliferum. Journal of agricultural and food chemistry, 65(7): 1337-1341.
24. Rajamanikyam M, Vadlapudi V, Upadhyayula SM. (2017). Endophytic fungi as novel resources of natural therapeutics. Brazilian Archives of Biology and Technology, 60.

25. Youssef F, Simal-Gandara J. (2021). Comprehensive Overview on the Chemistry and Biological Activities of Selected Alkaloid Producing Marine-Derived Fungi as a Valuable Reservoir of Drug Entities. Biomedicines, 9(5): 485.

26. Hawas UW, El-Desouky S, Abou El-Kassem L, Elkhateeb W. (2015). Alternariol derivatives from Alternaria alternata, an endophytic fungus residing in red sea soft coral, inhibit HCV NS3/4A protease. Applied biochemistry and microbiology, 51(5): 579-584.

27. Hawas UW, Abou El-Kassem LT. (2019). Anticancer and Antiviral Diketopiperazine Produced by the Red Sea Endophytic Fungus Penicillium chrysogenum. Letters in Organic Chemistry, 16(5): 409-414.

28. Tamminen A, Kramer A, Labes A, Wiebe MG. (2014). Production of scopularide A in submerged culture with Scopulariopsis brevicaulis. Microbial cell factories, 13(1): 1-7.

29. Yu Z, Lang G, Kajahn I, Schmaljohann R, Imhoff JF. (2008). Scopularides A and B, cyclodepsipeptides from a marine spongederived fungus, Scopulariopsis brevicaulis. Journal of Natural Products, 71(6): 1052-1054.

30. Lukassen MB, Saei W, Sondergaard TE, Tamminen A, Kumar A, Kempken F, Sørensen JL. (2015). Identification of the scopularide biosynthetic gene cluster in Scopulariopsis brevicaulis. Marine drugs, 13(7): 4331-4343.

31. Suleiman EA, Shigidi MT, Hassan SM. (2013). Activity of Scopulariopsis brevicaulis on Hyalomma anatolicum and Amblyomma lepidum (Acari: Ixodidae). 13(8): 667-675.
This work is licensed under Creative Commons Attribution 4.0 License
Submit Manuscript
To Submit Your Article Click Here:

DOI: $10.31579 / 2766-2314 / 067$
Ready to submit your research? Choose Auctores and benefit from:

$>$ fast, convenient online submission

$>$ rigorous peer review by experienced research in your field

$>$ rapid publication on acceptance

$>$ authors retain copyrights

$>$ unique DOI for all articles

$>$ immediate, unrestricted online access

At Auctores, research is always in progress.

Learn more https://auctoresonline.org/journals/biotechnology-andbioprocessing- 